\title{
Efficacy of Mirror Therapy Containing Functional Tasks in Poststroke Patients
}

\author{
Kil-Byung Lim, MD, Hong-Jae Lee, MD, Jeehyun Yoo, MD, Hyun-Ju Yun, MD, Hye-Jung Hwang, MPH \\ Department of Physical Medicine and Rehabilitation, Inje University Ilsan Paik Hospital, Goyang, Korea
}

\begin{abstract}
Objective To investigate the effect of mirror therapy containing functional tasks on upper extremity function and activities of daily living in patients with subacute stroke.

Methods The subjects were randomly divided into two groups: the mirror therapy group (30 patients) and the sham therapy group (30 patients). The mirror therapy group underwent a mirror therapy program together with conventional therapy for 20 minutes per day on 5 days per week for 4 weeks. The control group received a sham conventional therapy program under the same schedule as the mirror therapy group. The Fugl-Meyer Motor Function Assessment (FMA), Brunnstrom motor recovery stage, and Modified Barthel Index (MBI) were evaluated 4 weeks after the treatment.

Results The upper extremity function on the affected side and ability to perform daily life activities after the intervention were significantly improved in both groups. After 4 weeks of intervention, improvements in the FMA $(p=0.027)$ and MBI $(p=0.041)$ were significantly greater in the mirror therapy group than the sham therapy group. Conclusion In this study, we found that the mirror therapy containing functional task was effective in terms of improving the upper extremity functions and activities of daily living in patients with subacute stroke.
\end{abstract}

Keywords Mirror therapy, Upper extremity, Activities of daily living

\section{INTRODUCTION}

Hemiplegia is one of the most common and undesirable consequences of stroke. The disability in daily life is of longer duration for paralysis of the upper extremity than of the lower extremity. Functional recovery of the upper extremity includes grasping, holding, and manipulating objects, which requires the recruitment and complex integration of muscle activity from the shoulder to the fingers. In contrast, a minimal amount of recovery of the lower extremity may be sufficient to obtain functional ambulation [1]. It has been reported that up to $85 \%$ of stroke survivors experience hemiparesis and 55\%-75\% continue to have limitations in upper extremity function [2]. The paralyzed upper extremity, accompanied by the weakness of muscles, increased spasticity, sensory loss,

Received July 24, 2015; Accepted December 7, 2015

Corresponding author: Hyun-Ju Yun

Department of Physical Medicine and Rehabilitation, Inje University Ilsan Paik Hospital, 170 Juhwa-ro, Ilsanseo-gu, Goyang 10380, Korea. Tel: +82-31910-7440, Fax: +82-31-910-7446, E-mail: I9581@paik.ac.kr

ORCID: Kil-Byung Lim (http://orcid.org/0000-0001-8971-7486); Hong-Jae Lee (http://orcid.org/0000-0001-9813-4952); Jeehyun Yoo (http://orcid. org/0000-0002-1555-8029); Hyun-Ju Yun (http://orcid.org/0000-0002-4445-3680); Hye-Jung Hwang (http://orcid.org/0000-0002-5169-3033).

(c) This is an open-access article distributed under the terms of the Creative Commons Attribution Non-Commercial License (http://creativecommons.org/ licenses/by-nc/4.0) which permits unrestricted noncommercial use, distribution, and reproduction in any medium, provided the original work is properly cited. Copyright (c) 2016 by Korean Academy of Rehabilitation Medicine 
and muscle rigidity, is also the leading cause of serious discomfort and disability. Hence, functional recovery of the upper extremity is one of the main purposes of the rehabilitation of stroke survivors.

The brain tends to recognize visual feedback before proprioceptive or somatic feedback. Mirror therapy is based on the neuroplasticity suggested by this theory. The normal upper limb movement as seen in the mirror serves as the visual feedback necessary to stimulate the primary somatosensory cortex to induce movement of the paralyzed side [3]. Altschuler et al. [4] demonstrated improvement of movements in terms of range of motion, speed and accuracy through Fugl-Meyer Assessment (FMA) in poststroke patients who underwent mirror therapy. Yavuzer et al. [2] reported that mirror therapy in addition to a conventional rehabilitation program was beneficial in terms of motor recovery and upper limb functioning. These studies suggest that mirror therapy leads to better functional recovery of the upper extremities than does conventional therapy.

Functional task-oriented training recently applied to patients with stroke is more effective than the conventional therapy [5]. Recent studies have shown that taskoriented training tends to improve the functions of the upper extremity, but mostly in terms of balance with other body parts and balance while walking. Others have claimed that such training also helps patients take care of themselves [6,7]. A previous study reported motor improvement of a hemiplegic upper extremity in a group of patients who underwent specialized task-oriented training, such as plugging pegs or accumulating corns [8].

Task-oriented mirror therapy is conventional, movement-oriented mirror therapy with addition of functional tasks [9]. Achievement of positive effects of both the conventional and task-oriented therapies leads to optimum results of rehabilitation.

Therefore, the aim of this study was to demonstrate the effectiveness of task-oriented mirror therapy in patients with subacute stroke by analyzing the improvement in the functions of the upper extremity and activities of daily living in patients who underwent mirror therapy compared to those subjected to a sham treatment.

\section{MATERIALS AND METHODS}

\section{Study subjects}

The 60 subjects of this study were poststroke hemiplegia patients with upper extremity deficits who were hospitalized in the Department of Rehabilitation Medicine at Ilsan Paik Hospital from February to May 2012. The inclusion criteria were (1) a diagnosis of hemiplegia due to stroke within 6 months, (2) a score of 24 points or more on the Korean version of Mini-Mental State Examination, and (3) Brunnstrom stage of upper extremity recovery of 3 to 4 . The exclusion criteria were (1) musculoskeletal disease, (2) neglect, and (3) mental illness.

\section{Methods}

The subjects were randomly allocated to the mirror therapy group and sham therapy group using a randomization table. All patients completed the study. The mirror therapy group underwent mirror therapy with functional tasks with both hands for 20 minutes, and the sham therapy group underwent conventional therapy with functional tasks with both hands without a mir-

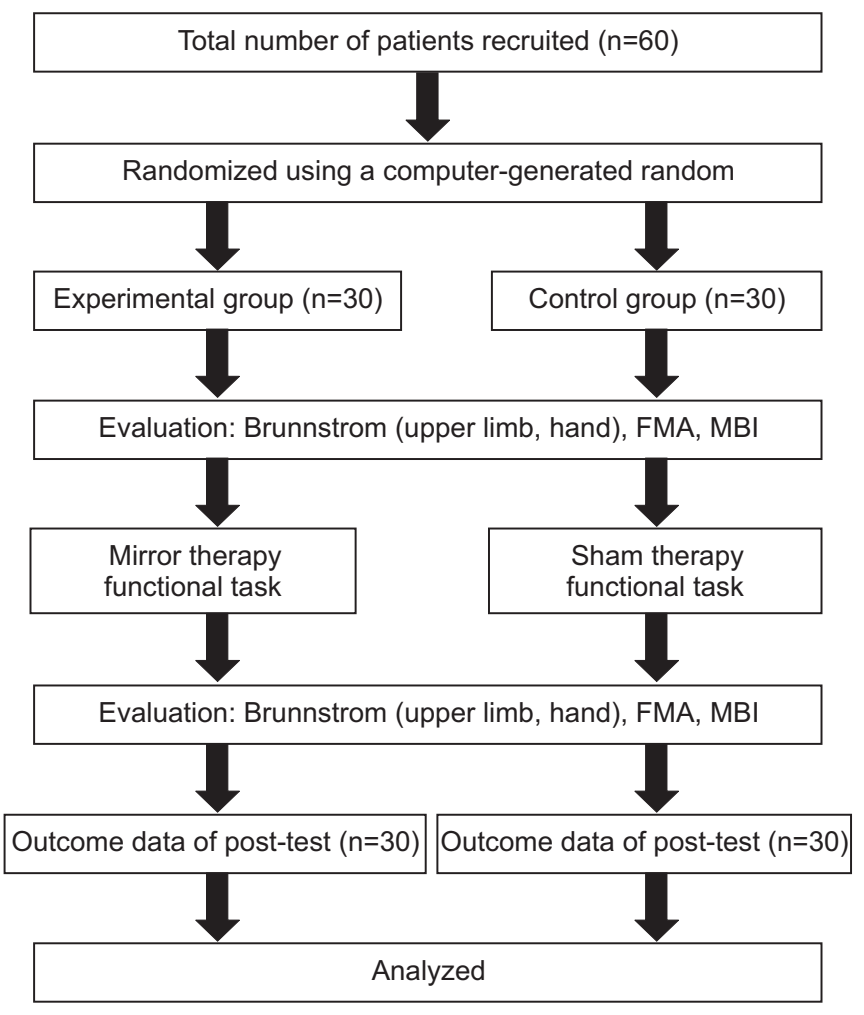

Fig. 1. Flow diagram of this study. FMA, Fugl-Meyer Assessment; MBI, Modified Barthel Index. 
ror for 20 minutes. The intervention was performed five times per week for 4 weeks. A therapist conducted a pretest before the intervention and post-test after 4 weeks of intervention. The methods are outlined below (Fig. 1).

\section{Mirror therapy}

Patients underwent task-oriented mirror therapy for 20 minutes by imitating the reflection of the normal upper limb in the mirror (Table 1). The patients attempted to move the hemiplegic upper limb in a manner identical to the normal limb reflected in the mirror under the direction of the therapist, who assisted the patients concentrating on their movements. Starting in the neutral position, the patients were asked to repeat each movement 20 times per set for three sets, with a 2-minute break between sets. There were also 2-minute intervals between each completed task (Fig. 2). The functional tasks planned for the first week were simple movements, such as forearm pronation-supination and wrist flexionextension. For the second week, the patients were asked to perform finger flexion-extension, counting numbers, tapping, and opposing. By the third week, they were to take on simple manipulating tasks, such as picking up coins and beans, flipping over cards and collecting blocks in a bin. During the fourth week, they moved on to more complicated tasks of plugging and unplugging pegboards, drawing simple figures, and coloring.

\section{Sham therapy}

The sham therapy group performed the same functional tasks over the same period; i.e., the patients' hemiplegic upper limb imitated the movements of normal hand under the direction of the therapist. However, a wood plate was placed between the hemiplegic upper limb and

Table 1. Mirror therapy containing functional task

\begin{tabular}{|c|c|c|}
\hline \multirow[t]{3}{*}{1 week } & Simple movement & Look at his hand reflected in the mirror \\
\hline & & Forearm pronation \& supination \\
\hline & & Wrist flexion \& extension \\
\hline \multirow[t]{2}{*}{2 weeks } & Simple movement & Finger flexion \& extension \\
\hline & & Counting/opposition/tapping \\
\hline \multirow[t]{3}{*}{3 weeks } & Simple task & Pick up a coin or bean \\
\hline & & Flip a card \\
\hline & & Put block into bucket \\
\hline \multirow[t]{3}{*}{4 weeks } & Complex task & Placing peg on a board \\
\hline & & Copying shapes on a paper \\
\hline & & Color in a drawing with crayons \\
\hline
\end{tabular}
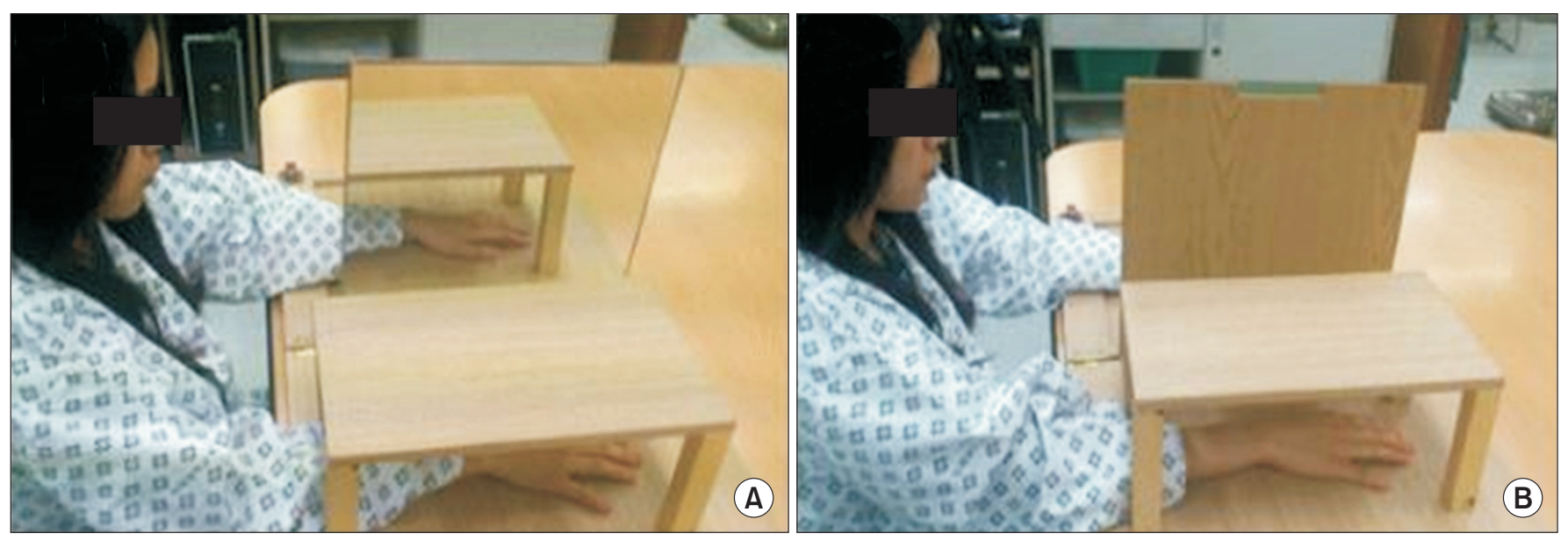

Fig. 2. (A) Mirror therapy and (B) sham therapy. 
the normal limb instead of a mirror (Fig. 2).

Tools

\section{Experimental tools}

All patients sat close to the hospital desk. The mirror therapy group patients were able to see the reflection of the normal upper limb through a vertically placed, 35 $\mathrm{cm} \times 35 \mathrm{~cm}$ mirror. For the sham therapy group, the wood plate obstructed the view of the normal upper limb.

\section{Measurement tools}

Fugl-Meyer Motor Function Assessment (FMA) and Brunnstrom stage were used to assess the functions of the hemiplegic upper limb. Activities of daily living were evaluated using the Modified Barthel Index (MBI).

\section{Analyses}

All data were statistically analyzed using SPSS ver. 19.0 for Windows (IBM, Armonk, NY, USA). The independent sample t-test was performed to assess the general characteristics of the mirror therapy and sham therapy groups, and the homogeneity between the abilities of activities of daily living and the functions of the hemiplegic upper limb in these two groups before the intervention. Chi-square test and Fisher exact test were performed to compare the Brunnstrom recovery stages of the hemiplegic upper limb and hand. A paired comparison t-test was used to evaluate the changes in the abilities of activities of daily living and functions of the hemiplegic upper limb before and after the intervention in the mirror therapy and sham therapy groups. An independent sample t-test was used to evaluate the postmortem changes between the groups. Statistical significance was accepted at $\mathrm{p}<0.05$ in this study.

\section{RESULTS}

\section{Subjects' general characteristics}

Sixty patients were divided into mirror therapy and sham therapy groups (30 patients in each group). There were 19 male and 11 female patients in the mirror therapy group, and 20 male and 10 female patients in the sham therapy group. The patients in the mirror therapy group were 65.3 years of age on average, compared to 64.5 years in the shame therapy group. In the mirror therapy group, 22 patients had cerebral hemorrhage and 8 had cerebral infarction. In the sham therapy group, 19 suffered cerebral hemorrhage and 11 cerebral infarction. In the mirror therapy group, 15 patients had hemiplegia on the right side and 15 on the left side. In the sham therapy group, 16 had hemiplegia on the right, and 14 on the left. The mirror therapy group patients were ill for an average of 49.4 days, compared to 53.7 days in the sham therapy group. There were no significant differences in the general characteristics of the patients between the groups $(p>0.05)$ (Table 2).

\section{Brunnstrom stage}

The Brunnstrom stage of the mirror therapy group and the sham therapy group before and after treatment of the hemiplegic upper limb did not differ significantly $(\mathrm{p}>0.05)$ (Table 3).

\section{FMA}

The functional changes to the hemiplegic upper limb between pre- and post-intervention are shown in Table

Table 2. General characteristics of the subjects

\begin{tabular}{lrrr}
\hline \multicolumn{1}{c}{ Characteristic } & $\begin{array}{r}\text { MTFT } \\
(\mathbf{n = 3 0})\end{array}$ & $\begin{array}{c}\text { STFT } \\
(\mathbf{n}=\mathbf{3 0})\end{array}$ & p-value \\
\hline Sex & & & \\
Male & $19(63)$ & $20(67)$ & 0.791 \\
\hline Female & $11(37)$ & $10(33)$ & \\
Mean age (yr) & 65.3 & 64.5 & 0.792 \\
Type of stroke & & & \\
ICH & $22(73)$ & $19(63)$ & 0.414 \\
\hline Ischemia & $8(27)$ & $11(37)$ & \\
Side of paresis & & & \\
Left & $15(50)$ & $16(53)$ & 0.800 \\
\hline Right & $15(50)$ & $14(47)$ & \\
Mean stroke duration (day) & 49.4 & 53.7 & 0.651 \\
\hline Brunnstrom stage & & & \\
\hline Upper limb & & & 0.573 \\
\hline III & $22(73)$ & $20(67)$ & \\
\hline IV & $8(27)$ & $10(33)$ & \\
\hline Hand & & & 0.999 \\
\hline III & $26(87)$ & $27(90)$ & \\
\hline IV & $4(13)$ & $3(10)$ & \\
\hline
\end{tabular}

Values are presented as number of patients (\%).

MTFT, mirror therapy containing functional task group; STFT, sham therapy containing functional task group. 
Table 3. Brunnstrom stage pre- and post-intervention

\begin{tabular}{|c|c|c|c|c|c|c|c|c|c|}
\hline & & \multicolumn{3}{|c|}{ Upper limb } & \multirow{2}{*}{ p-value } & \multicolumn{3}{|c|}{ Hand } & \multirow{2}{*}{ p -value } \\
\hline & & III & IV & V & & III & IV & V & \\
\hline \multirow[t]{2}{*}{ Pre } & MTFT & 22 & 8 & 0 & 0.573 & 26 & 4 & 0 & 0.999 \\
\hline & STFT & 20 & 10 & 0 & & 27 & 3 & 0 & \\
\hline \multirow[t]{2}{*}{ Post } & MTFT & 6 & 16 & 8 & 0.420 & 9 & 13 & 8 & 0.407 \\
\hline & STFT & 8 & 18 & 4 & & 12 & 14 & 4 & \\
\hline
\end{tabular}

Values are presented as number of patients.

MTFT, mirror therapy containing functional task group; STFT, sham therapy containing functional task group.

Table 4. Comparison of FMA \& MBI pre- and post-intervention

\begin{tabular}{ccccccc} 
& \multicolumn{2}{c}{ MTFT } & \multirow{2}{*}{ p-value } & \multicolumn{2}{c}{ STFT } & \multirow{2}{*}{ p-value } \\
\cline { 2 - 3 } & Pre & Post & & Pre & Post & \\
\hline FMA & $26.93 \pm 6.32$ & $41.40 \pm 9.04$ & $<0.001$ & $26.90 \pm 6.32$ & $37.40 \pm 9.04$ & $<0.001$ \\
MBI & $28.67 \pm 7.57$ & $59.63 \pm 15.58$ & $<0.001$ & $26.77 \pm 6.60$ & $51.37 \pm 16.34$ & $<0.001$ \\
\hline
\end{tabular}

Values are presented as means \pm standard deviation.

MTFT, mirror therapy containing functional task group; STFT, sham therapy containing functional task group; FMA, Fugl-Meyer Assessment; MBI, Modified Barthel Index.

Table 5. Assessments at baseline and after treatment

\begin{tabular}{lllc}
\hline & \multicolumn{1}{c}{ MTFT } & \multicolumn{1}{c}{ STFT } & p-value \\
\hline FMA $(\Delta)$ & $14.47 \pm 6.85$ & $10.50 \pm 6.69$ & 0.027 \\
$\operatorname{MBI}(\Delta)$ & $30.97 \pm 10.81$ & $24.60 \pm 12.74$ & 0.041 \\
\hline
\end{tabular}

Values are presented as mean \pm standard deviation.

MTFT, mirror therapy containing functional task group; STFT, sham therapy containing functional task group; FMA, Fugl-Meyer Assessment; MBI, Modified Barthel Index.

4. The FMA score increased significantly from $6.93 \pm 6.32$ to $41.40 \pm 9.04$ in the mirror therapy group ( $\mathrm{p}<0.001$ ), and from $26.90 \pm 6.32$ to $37.40 \pm 9.04$ in the sham therapy group ( $<<0.001)$. Consequently, both groups demonstrated significant functional developments of the hemiplegic upper limb post-therapy. The degree of recovery was greater in the mirror therapy than the sham therapy group (14.47 \pm 6.85 mirror therapy and $10.50 \pm 6.69$ sham therapy, respectively) (Table 5).

\section{$\mathrm{MBI}$}

The performance in activities of daily living between pre- and post-intervention were assessed using the MBI (Table 4). There were significant increases in both groups: from $28.67 \pm 7.57$ to $59.63 \pm 15.58$ in the mirror therapy group ( $\mathrm{p}<0.001$ ) and from $26.77 \pm 6.60$ to $51.37 \pm 16.34$ in the sham therapy group $(p<0.001)$. The degree of recovery was greater in the mirror therapy than the sham therapy group (30.97 \pm 10.81 mirror therapy and $24.60 \pm 12.74$ sham therapy, respectively) (Table 5).

\section{DISCUSSION}

Our findings indicate that the functions of the hemiplegic upper limb and the performance of activities of daily living in patients with subacute stroke improved to a greater degree in patients subjected to both the task-oriented and mirror therapy for 4 weeks than those who did not receive the mirror therapy. The results corresponded with previous reports that mirror therapy in patients with stroke strengthened the capacity and functions of locomotion. The functions of the hemiplegic upper limb and the abilities of activities of daily living in the task-oriented sham therapy group showed improvements, but after the intervention, Fugl-Meyer scores and the performance of activities of daily living increased to a greater degree in the task-oriented mirror therapy group than the sham therapy group.

Several mechanisms may explain the effects of mirror therapy on locomotion capacity. First, the mirror therapy facilitates recovery of locomotion ability by visually stimulating the hemiplegic upper limb using the reflection of the normal side. Altschuler et al. [4] reported that the reflected image of the hemiplegic hand created the delu- 
sion that it was normal, which facilitated rehabilitation by replacing the lost proprioceptive sense to assist reconstruction of the total motor cortex and stimulation of whole-body activity. Funase et al. [10] demonstrated that passive observation and imitation of specific movements in mirror therapy stimulated activities of the spinal cord and cerebral cortex.

Second, the mirror neuron system accelerates the recovery of motor ability. The mirror neurons are visuomotor neurons activated when observing, imagining, or attempting to execute movements [11]. This is the theoretical framework of process of learning new exercise techniques through observation [12]. Stevens reported that mirror therapy was related to motor imagery and improved the motor activities of a hemiplegic extremity using the visual feedback brought on by imagined action [13]. Fadiga and Craighero [14] demonstrated that the passive observation of motions through the mirror neuron system boosted activation of the primary motor area, which controlled the movements performed by the patient.

Thirdly, the simultaneous motion of both limbs induces additional stimulation of the paralyzed unilateral cerebral cortex through interactions with the stimulated normal cerebral cortex. Summers et al. [15] reported that exercising both the normal and hemiplegic sides was more effective in restoring upper limb functions and muscle strength than working the hemiplegic side alone. Cauraugh and Summers [16] hypothesized that concurrent exercise of both sides would control the excessive suppression of transmission due to balance between the hemiplegic and normal limbs. This hypothesis supports the conclusion that mirror therapy involving the exercise of both limbs is more effective than exercise of only the hemiplegic side.

Repetitive task-oriented training fosters the recovery of motor abilities for stroke patients, and improves their ability to carry out activities of daily living $[9,17]$.

In task-oriented training, patients reduce the frequency of inappropriate movements by repeatedly undertaking a wide range of movements, which in turn develops their adaptability to other specialized tasks [18]. The patients grow accustomed to the circumstances by learning taskspecific strategies. Moreover, task-oriented training also improved the functions of the musculoskeletal and neuromuscular systems [19].
Functional task-oriented therapy could lead to recovery of the motor abilities of the hemiplegic upper limb based on interactions with the normal upper limb. Interlimb transfer refers to functional improvement of the hemiplegic upper limb by transfer of the effects of training the normal upper limb to the hemiplegic upper limb. Yoo et al. [8] divided 20 post-stroke hemiplegic patients into two groups: one group was asked to undertake functional tasks with the normal upper limb, such as plugging pegs or piling up cones, and the other to perform simple tasks comprising only movements. The group that performed the functional tasks with the normal upper limb showed improvements in the motor abilities of the hemiplegic upper limb by interlimb transfer. Therefore, functional task-oriented therapy in the normal limb, rather than simple motions, was more effective for recovery of the hemiplegic upper limb.

A study that attempted to combine mirror therapy with other therapies showed improvements in the hand functions of post-stroke patients who underwent both mirror therapy and neuromuscular electric stimulation, compared to those who underwent each therapy separately [20]. Indeed, undergoing both mirror therapy and limited motion therapy of the normal upper limb was more effective in improving hand functions of patients with subacute stroke than performing each therapy separately [21].

Arya et al. [22] compared a group of patients who underwent functional tasks and mirror therapy with a group that received conventional treatment. The former group showed a more significant improvement in Fugl-Meyer Assessment and Brunnstrom stage.

Based on these theories, therapies with functional tasks were applied to two groups and changes in their ability to undertake of activities of daily living and upper limb function were compared.

The study also anticipated the effects of both mirror therapy and functional tasks. Use of methods stressing active exercise and task-specific training maximized the functional abilities and potentially induced reorganization of the brain [23], with the goal of improving upper limb function and the ability to carry out activities of daily living.

Working under the premise that mirror therapy exerts a positive effect on upper limb mobility and function of post-stroke patients, this study examined the Brunnstrom 
stage, FMA, and MBI scores of the upper limb and hands pre- and post-intervention. The results indicated improvements in upper limb functions and the ability to perform activities of daily living.

Both groups showed increases in the Brunnstrom stage, which indicates the repair stages of neurons, after 4 weeks of intervention, albeit not significantly so. This suggests that the Brunnstrom stage, scored from level 1 to 6 , may not be appropriate to assess the effects of mirror therapy because of its lack of sensitivity.

Also, because the subjects were in-patients who were undergoing comprehensive rehabilitation in addition to mirror therapy, effects of other occupational therapy and physiotherapy cannot be ruled out. Thus a further study controlling for such potential confounders is required.

FMA scores increased in the mirror therapy group after intervention. The sham therapy group also exhibited an increased FMA score after intervention, but of a lesser magnitude. This result is in agreement with the report by Stevens of the effectiveness of mirror therapy in stroke patients in terms of improving their upper limb functions [13].

In terms of the ability to perform activities of daily living, MBI scores increased in both the mirror therapy group and the sham therapy group; the magnitude of the increase was greater in the former.

The increase in such abilities in both groups may be due to stimulation of the proprioceptive sense through movements of the upper limbs during sham therapy. However, since the increase in the MBI score after therapy was greater in the mirror therapy group, mirror therapy is more effective in terms of improving the ability to perform activities of daily living.

The limitations of this study were as follows. First, only short-term effects were evaluated because mirror therapy was of 4-week duration. Second, the subjects were inpatients at a particular hospital who met the inclusion criteria, and the effects of other forms of rehabilitation received by the patients could not be ruled out. Third, the patients were capable of communication with others as their cognitive functions were not damaged. Thus it was difficult to generalize the results to the entire population of hemiplegic patients.

Unlike other forms of therapy, performance of mirror therapy with functional tasks is easy, and thus can readily applied in the clinic [24]. It is also non-invasive and causes no side-effects, making it safe for patients [25]. Dohle et al. [26] reported that mirror therapy led to improvements in upper limb and hand functions in 36 patients with acute ischemic stroke, regardless of their lesions, suggesting that mirror therapy can be performed on different types of patients. Furthermore, patients can undergo this form of therapy without the aid of a therapist indeed, the therapy can be performed at home.

In conclusion, mirror therapy containing functional tasks exerted significant effects in terms of improving the upper limb functions and the ability to perform activities of daily living among patients with subacute stroke. Based on these findings, mirror therapy with functional tasks can serve as an alternative rehabilitation method for stroke patients.

\section{CONFLICT OF INTEREST}

No potential conflict of interest relevant to this article was reported.

\section{REFERENCES}

1. Feys HM, De Weerdt WJ, Selz BE, Cox Steck GA, Spichiger R, Vereeck LE, et al. Effect of a therapeutic intervention for the hemiplegic upper limb in the acute phase after stroke: a single-blind, randomized, controlled multicenter trial. Stroke 1998;29:785-92.

2. Yavuzer G, Selles R, Sezer N, Sutbeyaz S, Bussmann JB, Koseoglu F, et al. Mirror therapy improves hand function in subacute stroke: a randomized controlled trial. Arch Phys Med Rehabil 2008;89:393-8.

3. Garry MI, Loftus A, Summers JJ. Mirror, mirror on the wall: viewing a mirror reflection of unilateral hand movements facilitates ipsilateral M1 excitability. Exp Brain Res 2005;163:118-22.

4. Altschuler EL, Wisdom SB, Stone L, Foster C, Galasko D, Llewellyn DM, et al. Rehabilitation of hemiparesis after stroke with a mirror. Lancet 1999;353:2035-6.

5. Villiger M, Chandrasekharan S, Welsh TN. Activity of human motor system during action observation is modulated by object presence. Exp Brain Res 2011; 209:85-93.

6. Salbach NM, Mayo NE, Wood-Dauphinee S, Hanley JA, Richards CL, Cote R. A task-orientated intervention enhances walking distance and speed in the first 
year post stroke: a randomized controlled trial. Clin Rehabil 2004;18:509-19.

7. Choi JU, Kang SH. The effects of patient-centered taskoriented training on balance activities of daily living and self-efficacy following stroke. J Phys Ther Sci 2015;27:2985-8.

8. Yoo IG, Jung MY, Yoo EY, Park SH, Park JH, Lee J, et al. Effect of specialized task training of each hemisphere on interlimb transfer in individuals with hemiparesis. NeuroRehabilitation 2013;32:609-15.

9. Arya KN, Verma R, Garg RK, Sharma VP, Agarwal M, Aggarwal GG. Meaningful task-specific training (MTST) for stroke rehabilitation: a randomized controlled trial. Top Stroke Rehabil 2012;19:193-211.

10. Funase $K$, Tabira T, Higashi $T$, Liang $N$, Kasai T. Increased corticospinal excitability during direct observation of self-movement and indirect observation with a mirror box. Neurosci Lett 2007;419:108-12.

11. Cattaneo L, Rizzolatti G. The mirror neuron system. Arch Neurol 2009;66:557-60.

12. Buccino G, Binkofski F, Riggio L. The mirror neuron system and action recognition. Brain Lang 2004;89: 370-6.

13. Stevens JA, Stoykov ME. Using motor imagery in the rehabilitation of hemiparesis. Arch Phys Med Rehabil 2003;84:1090-2.

14. Fadiga L, Craighero L. Electrophysiology of action representation. J Clin Neurophysiol 2004;21:157-69.

15. Summers JJ, Kagerer FA, Garry MI, Hiraga CY, Loftus A, Cauraugh JH. Bilateral and unilateral movement training on upper limb function in chronic stroke patients: a TMS study. J Neurol Sci 2007;252:76-82.

16. Cauraugh JH, Summers JJ. Neural plasticity and bilateral movements: a rehabilitation approach for chronic stroke. Prog Neurobiol 2005;75:309-20.

17. Carr JH, Shepherd RB. Stroke rehabilitation: guidelines for exercise and training to optimize motor skill.
London: Buttlerworth-Heinemann; 2003.

18. Thielman GT, Dean CM, Gentile AM. Rehabilitation of reaching after stroke: task-related training versus progressive resistive exercise. Arch Phys Med Rehabil 2004;85:1613-8.

19. Yang YR, Wang RY, Lin KH, Chu MY, Chan RC. Taskoriented progressive resistance strength training improves muscle strength and functional performance in individuals with stroke. Clin Rehabil 2006;20:86070.

20. Yun GJ, Chun MH, Park JY, Kim BR. The synergic effects of mirror therapy and neuromuscular electrical stimulation for hand function in stroke patients. Ann Rehabil Med 2011;35:316-21.

21. Yoon JA, Koo BI, Shin MJ, Shin YB, Ko HY, Shin YI. Effect of constraint-induced movement therapy and mirror therapy for patients with subacute stroke. Ann Rehabil Med 2014;38:458-66.

22. Arya KN, Pandian S, Kumar D, Puri V. Task-based mirror therapy augmenting motor recovery in poststroke hemiparesis: a randomized controlled trial. J Stroke Cerebrovasc Dis 2015;24:1738-48.

23. Shepherd RB. Exercise and training to optimize functional motor performance in stroke: driving neural reorganization? Neural Plast 2001;8:121-9.

24. Invernizzi M, Negrini S, Carda S, Lanzotti L, Cisari C, Baricich $\mathrm{A}$. The value of adding mirror therapy for upper limb motor recovery of subacute stroke patients: a randomized controlled trial. Eur J Phys Rehabil Med 2013;49:311-7.

25. Thieme H, Mehrholz J, Pohl M, Behrens J, Dohle C. Mirror therapy for improving motor function after stroke. Stroke 2013;44:e1-2.

26. Dohle C, Püllen J, Nakaten A, Kust J, Rietz C, Karbe H. Mirror therapy promotes recovery from severe hemiparesis: a randomized controlled trial. Neurorehabil Neural Repair 2009;23:209-17. 